\title{
Determinação da atividade antioxidante e do teor total de polifenol em amostras de chá de ervas comercializadas em sachets
}

\author{
Determination of total antioxidant activity and total content \\ of polyphenols in samples of tea leaves marketed in bags
}

Tieme Nakamura, Fátima Santos Silva, Diego Xavier da Silva, Maryane Woth de Souza, Horacio Dorigan Moya

DOI: http://dx.doi.org/10.7322/abcshs.v38i1.3

\section{RESUMO}

Objetivo: Os chás de ervas são tradicionalmente utilizados na medicina popular em muitas regiões do Brasil. Os chás contêm compostos antioxidantes que combatem o stress oxidativo e seu consumo tem sido associado à diminuição dos níveis de colesterol, pressão arterial e até de doenças cardiovasculares. O objetivo deste estudo foi determinar a capacidade antioxidante total, o teor total de polifenóis, o consumo (scavenging) de $\mathrm{H}_{2} \mathrm{O}_{2}$ e a presença de outros grupos de compostos antioxidantes em 43 amostras de chás em sachets. Métodos: 0 método CUPRAC (cupric ion reducing antioxidant capacity) foi utilizado para determinar a capacidade antioxidante total. O teor total de polifenóis foi obtido com o uso do reagente de Folin-Ciocalteu; o ensaio de scavenging baseou-se no consumo de solução de $\mathrm{H}_{2} \mathrm{O}_{2}$ após adição do chá; e a presença de flavonóides, carotenos e catequinas foi investigada por cromatografia em papel. Resultados: A capacidade antioxidante total nas amostras analisadas seguiu a ordem: camomila $>$ hortelã $>$ carqueja $>$ cidreira $>$ boldo $>$ verde $>$ mate $>$ preto $>$ branco $>$ erva doce. O teor total de polifenóis obedeceu à sequência: branco $>$ hortelã $>$ preto $>$ mate $>$ boldo $>$ verde $>$ camomila $>$ carqueja $>$ cidreira $>$ erva doce. As divergências encontradas entre as amostras de um mesmo grupo de chá podem ser atribuídas à época da colheita, ao tipo de solo, local de plantio, variações climáticas e partes da planta utilizadas na elaboração dos sachets. Conclusão: Concluise que todas as amostras analisadas apresentaram capacidade antioxidante e consumo de $\mathrm{H}_{2} \mathrm{O}_{2}$. Em apenas uma delas não foi possível detectar flavonóides, carotenos ou catequinas.

Palavras-chave: chá; bebidas; polifenóis; flavonóides; carotenóides; catequinas.

\begin{abstract}
Objective: Tea leaves are traditionally used in folk medicine in many regions of Brazil. They contain antioxidant compounds that can protect against oxidative stress and their regular intake have been associated with decreased of cholesterol levels, blood pressure and, thereby, with the lowered risk of coronary heart disease. The objective of this study was to determine the total antioxidant capacity, the total polyphenols content, scavenging of $\mathrm{H}_{2} \mathrm{O}_{2}$ and presence of other groups of antioxidant compounds in 43 tea samples packed in bags. Methods: The CUPRAC method (cupric ion reducing antioxidant capacity) was used to quantify the total antioxidant capacity. The polyphenols content was performed using the Folin-Ciocalteu reagent. The scavenging assay was based on the consumption of $\mathrm{H}_{2} \mathrm{O}_{2}$ after addition of tea; the presence of flavonoids, carotenes and catechins was evaluated by paper chromatography. Results: The total antioxidant capacity found in tea samples followed the order: chamomile $>$ mint $>$ carqueja $>$ balm $>$ boldo $>$ green $>$ mate $>$ black $>$ white $>$ fennel. For total polyphenol content the order was: white $>$ mint $>$ black $>$ matte $>$ boldo $>$ green $>$ chamomile $>$ carqueja $>$ balm $>$ fennel. The differences found in the samples from the same kind of tea can be attributed to the harvest season, soil type, planting location, climate differences and from the parts of the vegetal material used in the preparation of the tea bags. Conclusion: All samples analyzed presented antioxidant activity and ability to scavenge $\mathrm{H}_{2} \mathrm{O}_{2}$. It was not possible to detect flavonoids, carotenes and catechins in only one sample.
\end{abstract}

Keywords: tea; beverages; polyphenols; flavonoids; carotenoids; catechins.

Recebido em: 03/12/2012

Revisado em: 08/02/2013

Aprovado em: 14/02/2013

Endereço para correspondência

Horacio Dorigan Moya - Faculdade de Medicina da Fundação do ABC (FMABC) - Centro de Estudos, Pesquisa, Prevenção e Tratamento em Saúde (CEPES) - Avenida Príncipe de Gales, 821 - CEP: 09060-650 - Santo André (SP), Brasil - E-mail: horacio.moya@fmabc.br.

Fonte de financiamento: Fundação de Amparo à Pesquisa do Estado de São Paulo (FAPESP).

Conflito de interesse: nada a declarar. 


\section{INTRODUÇÃO}

Estudos epidemiológicos e ensaios clínicos têm estabelecido relação direta entre a ingestão de frutas e hortaliças e a diminuição da ocorrência de distúrbios relacionados ao stress oxidativo que ocorre devido ao desequilíbrio entre o balanço antioxidante e pró-oxidante, favorecendo o último e originando danos em biomoléculas como proteínas e DNA. A esses danos é atribuído grande número de patologias, incluindo doenças cardiovasculares ou relacionadas ao envelhecimento e até mesmo certos tipos de câncer ${ }^{1-3}$.

Acredita-se que os componentes presentes nos alimentos que contribuam mais ativamente para essa proteção sejam as vitaminas (E e C), carotenos e polifenóis (ex.: flavonóides e catequinas), os quais atuam como antioxidantes (AO's). Estes desempenham papel importante no sistema de defesa do corpo, consumindo espécies reativas de oxigênio (ROS) e de nitrogênio (RNS) como $\mathrm{O}_{2}^{--}, \mathrm{HO}, \mathrm{H}_{2} \mathrm{O}_{2}, \mathrm{ONOO}^{-}$, $\mathrm{ROO}$; etc., que são subprodutos nocivos gerados durante o processo normal de respiração das células aeróbicas $^{1,2,4}$. Assim, incrementar a dieta com a ingestão baseada em alimentos contendo compostos AO's deve ajudar a manter um "estado antioxidante" balanceado e, por conseguinte, permitir uma função fisiológica adequada em um sistema vivo ${ }^{5}$.

Essa recente preocupação com o stress oxidativo e o "estado antioxidante" tem, como consequência, aumentado o interesse em quantificar os AO's presentes nos alimentos, pois muitos compostos fitoquímicos nos vegetais rotineiramente ingeridos são importantes fontes exógenas desses AO’s. Além dos inúmeros compostos AO's presentes nos alimentos, outros ainda podem ser adicionados como aditivos (ex.: vitamina E, BHT, BHA, etc.) para impedir que o alimento se torne rançoso devido à oxidação lipídica.

Observa-se, porém, que a maioria dos alimentos industrializados apresenta em suas embalagens tabelas de valores nutricionais que expressam a quantidade total de certos componentes, como gorduras, proteínas, fibras, carboidratos, sódio, etc., e até calorias. Estes valores são destinados a fornecer informações úteis para os consumidores. Todavia, embora os AO's sejam reconhecidamente importantes, não existe ainda nenhum índice nutricional da "atividade antioxidante" ou da "capacidade antioxidante total" disponível nos rótulos desses produtos.

Isso pode ser atribuído, em parte, à falta de um procedimento padrão e universalmente aceito para a quantificação dessa capacidade antioxidante total (CAT). De fato, devido às diferentes características químicas das reações envolvidas nos métodos disponíveis na literatura para quantificar a CAT, nenhum ensaio isolado reflete com exatidão a atividade antioxidante de um sistema tão complexo ${ }^{6,7}$. Em alguns países, a indústria alimentícia tem aceitado e adotado o método denominado ORAC (oxygen radical absorbance capacity $)^{7}$ para a determinação da CAT de seus produtos e incluído os valores obtidos com esse método nos rótulos dos seus produtos nutracêuticos ${ }^{8}$. No Brasil, isso ainda não é realizado.
O chá, bebida mais consumida em todo o mundo, tem uso tradicional na cultura brasileira e é consumido em muitas partes do País na medicina popular. Pesquisas têm associado o consumo de chás à redução do risco de desenvolvimento de doenças cardiovasculares, diminuindo os níveis de colesterol total e da pressão arterial. Estudos recentes realizados em animais de laboratórios demonstraram que o consumo adequado de chá pode prevenir a formação de diversos tipos de câncer, como de pele, pulmão, esôfago, estômago, intestino delgado, cólon, bexiga, fígado, pâncreas, próstata e glândulas mamárias ${ }^{9}$, e também pode atuar em um sinergismo positivo com administração de drogas antitumorais ${ }^{10}$.

Neste trabalho, a CAT foi determinada em 43 amostras de dez diferentes tipos de ervas de chás (hortelã - Mentha piperita L. e/ou Mentha arvensis L.; erva cidreira - Cymbopogon citratus S. e/ou Melissa officinalis L.; erva doce - Pimpinella anisum L. e/ou Foeniculum vulgare; camomila - Matricaria chamomilla L., Matricaria recutita e/ou Chamomilla recutita L.; mate - Ilex paraguariensis St. Hill; boldo - Peumus boldus, Molina; carqueja - Baccharis genisteiloides (Lamarck) Person; branco, verde e preto - Camellia sinensis L. Kuntze), comercialmente disponíveis na região da Grande São Paulo. O método CUPRAC (cupric ion reducing antioxidant capacity) já foi anteriormente utilizado para a determinação da CAT em amostras de chás ${ }^{11}$, se baseia na variação da coloração dos complexos de $\mathrm{Cu}$ (II) formados com o ligante neocuproína ${ }^{12}$ e utiliza a espectrofotometria, técnica bastante comum em laboratórios analíticos.

Paralelamente determinou-se o teor total de polifenol (TTP) nas mesmas amostras. Aos compostos polifenólicos, constituintes naturais da ervas de chás, são atribuídos benefícios à saúde humana devido às suas propriedades antioxidantes que interrompem a cadeia oxidativa ${ }^{13}$. Entre os mecanismos propostos para essa atividade antioxidante, incluem-se a despolarização de elétrons, a formação de ligações de hidrogênio intramoleculares e o rearranjo da estrutura molecular. Polifenóis também podem evitar reações de óxido redução por meio da quelação de íons de cobre e de ferro, que catalisam in vivo a formação de ROS e RNS ${ }^{14}$. O TTP nas amostras de chás foi determinado por espectrofotometria, utilizando o reagente de Folin-Ciocalteu, conforme recomendado pela Farmacopeia Brasileira para a quantificação de TTP em extratos vegetais ${ }^{15}$.

Há muito tempo sabe-se que peróxido de hidrogênio $\left(\mathrm{H}_{2} \mathrm{O}_{2}\right)$ é um importante contribuinte para o stress oxidativo e que sua presença promove a formação de câncer em pele de ratos ${ }^{16}$. Em níveis elevados de concentração, $\mathrm{H}_{2} \mathrm{O}_{2}$ induz à apoptose em células de mamíferos ${ }^{17}$ e acredita-se que esteja envolvido na metástase tumoral ${ }^{18}$. Por isso, a capacidade de consumo (scavenging) de $\mathrm{H}_{2} \mathrm{O}_{2}$ pelas mesmas amostras de chás também foi avaliada.

A presença de outros grupos de compostos AO's, como flavonóides, catequinas e carotenos, foi investigada por cromatografia em papel.

Os flavonóides (quercetina, kaempferol, luteolina, rutina, miricetina, etc.) são compostos polifenólicos largamente encontrados em vegetais. São responsáveis pela inibição de oxidação do ácido linoléico e pela oxidação do LDL, peroxidação de fosfolipídeos 
da membrana, peroxidação lipídica microssomal e mitocondrial, peroxidação de eritrócitos e fotoxidação e peroxidação de cloroplastos $^{19}$. Estudos demonstraram que certos flavonóides podem agir como indutores de apoptose em células de câncer do cólon ${ }^{20}$ e de mama ${ }^{21}$ humanos, além de inibir marcadamente a formação de câncer de pele em camundongos ${ }^{22}$.

Outro grupo importante de fitonutrientes polifenólicos são as catequinas, compostos incolores, solúveis em água e normalmente divididos em epicatequinas, galato de epicatequinas, epigalocatequinas e galato de epigalocatequina, sendo o último presente em grande quantidade nas ervas dos chás. No chá verde, encontra-se grande quantidade de catequinas, e esta singularidade tornou possíveis estudos utilizando o chá feito com essa erva para verificar a ação preventiva de alguns tipos de câncer em órgãos humanos ${ }^{23}$.

Carotenos são pigmentos orgânicos encontrados nos vegetais e essenciais para a vida. Como o ser humano não consegue sintetizá-los, devem ser ingeridos pela alimentação. Carotenos apolares (ex.: $\beta$-caroteno e licopeno) e polares (ex.: luteína e zeaxantina) apresentam comprovadas propriedades antioxidantes, e diversos estudos têm atribuído a esses compostos também atividade anticancerígena ${ }^{24,25}$.

Ao contrário de outros nutrientes, os AO's presentes nos vegetais são compostos quimicamente muito diferentes, o que efetivamente dificulta a adoção de um único método para avaliar a atividade an-

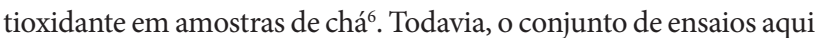
apresentado pode servir como um guia na escolha da bebida a ser consumida ou servir como um modelo de estudo para o controle de qualidade de produtos fitoterápicos industrializados.

\section{MÉTODOS}

\section{Equipamentos e materiais}

As medições espectrofotométricas foram realizadas no espectrofotômetro HPUV 8453 (Agilent) utilizando cubeta de vidro e de quartzo, ambas com 1,00 cm de caminho ótico.

Papel para cromatografia Whatman TM Grade 1 (SigmaAldrich), usado em todos os ensaios cromatográficos, foi seco em estufa profissional Line SX 450 (Sterilifer).

Translluminator UV ZT-21 (Crystal Bioglow) foi utilizado para visualização dos mesmos ensaios cromatográficos.

\section{Reagentes e soluções}

Todas as soluções e diluições foram preparadas com água obtida por osmose reversa (Quimis Q842-210), exceto quando mencionado outro solvente.

Solução padrão de ácido gálico $\left(\geq 98 \%, \mathrm{C}_{7} \mathrm{H}_{6} \mathrm{O}_{5} \cdot \mathrm{H}_{2} \mathrm{O}, \mathrm{MM}\right.$ $188,13 \mathrm{~g} \mathrm{~mol}^{-1}$, Carlo Erba) $0,188 \mathrm{mg} \mathrm{mL}^{-1}$ foi preparada diariamente por dissolução de $0,0188 \mathrm{~g}$ em água em balão volumétrico de 100,0 mL. A partir dessa solução obteve-se solução diluída $0,0188 \mathrm{mg} \mathrm{mL}^{-1}$.

Reagente de Folin-Ciocalteu (FC) foi preparado dissolvendo $10,0 \mathrm{~g}$ de tungstato de sódio $\left(\mathrm{Na}_{2} \mathrm{WO}_{4} \cdot 2 \mathrm{H}_{2} \mathrm{O}, \mathrm{MM} 329,86 \mathrm{~g} \mathrm{~mol}^{-1}\right.$,
Synth), 2,0 g de ácido fosfomolíbdico $\left(\mathrm{H}_{3} \mathrm{PMo}_{12} \mathrm{O}_{40}, \mathrm{MM} 1825\right.$, $25 \mathrm{~g} \mathrm{~mol}^{-1}$, Sigma-Aldrich) e 50,0 $\mathrm{mL}$ de ácido fosfórico $\left(\mathrm{H}_{3} \mathrm{PO}_{4}\right.$, $85 \%, 1,71 \mathrm{~g} \mathrm{~cm}^{-3}$, Merck) em 75,0 mL de água. Esta mistura foi aquecida sob refluxo durante duas horas e depois de atingir a temperatura ambiente foi transferida para um balão volumétrico de $100,0 \mathrm{~mL}$, sendo o volume completado com água. O reagente foi mantido a $8^{\circ} \mathrm{C}$ e quando adquiriu cor esverdeada foi regenerado por ebulição com algumas gotas de bromo liquido, $\mathrm{Br}_{2}$, somente até o reaparecimento da coloração amarela ${ }^{15}$.

Solução de carbonato de sódio $\left(\mathrm{Na}_{2} \mathrm{CO}_{3}, \mathrm{MM} \mathrm{105,99} \mathrm{g} \mathrm{mol}^{-1}\right.$, Carlo Erba) a 10\% foi preparada dissolvendo $10 \mathrm{~g}$ do sal em água em balão volumétrico de 100,0 mL.

Solução de perclorato de cobre(II), $\mathrm{Cu}\left(\mathrm{ClO}_{4}\right)_{2}, 2,3 \mathrm{~mol} \mathrm{~L}^{-1}$ foi preparada a partir da reação de carbonato de cobre(II), $\mathrm{CuCO}_{3}$, Fluka Chemie A.G, com um ligeiro excesso de ácido perclórico

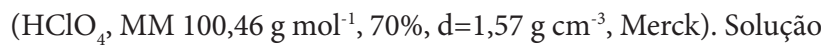
$9,31 \times 10^{-2} \mathrm{~mol} \mathrm{~L}^{-1}$ foi obtida por diluição, e a padronização foi realizada por titulação complexométrica com EDTA ${ }^{26}$.

Solução de neocuproína monohidratada (NC), na forma de cloridrato, $\left(\mathrm{C}_{14} \mathrm{H}_{12} \mathrm{~N}_{2} \cdot \mathrm{HCl} \cdot \mathrm{H}_{2} \mathrm{O}, \mathrm{MM} 262,73 \mathrm{~g} \mathrm{~mol}^{-1}\right.$, Fluka) $1,22 \times 10^{-2} \mathrm{~mol} \mathrm{~L}^{-1}$ foi preparada por dissolução de $0,3201 \mathrm{~g}$ em etanol (99,5\%, Synth) em balão volumétrico de 100,0 mL.

Solução de acetato de amônio $\left(\mathrm{CH}_{3} \mathrm{COONH}_{4}, \mathrm{MM} 77,08 \mathrm{~g} \mathrm{~mol}^{-1}\right.$, QM Reagentes) 2,0 $\mathrm{mol} \mathrm{L}^{-1}$ foi preparada por dissolução de 38,54 g em água em balão volumétrico de 250,0 mL e utilizada como solução tampão (pH 7,0).

Solução padrão de ácido ascórbico $\left(99,7 \%, \mathrm{C}_{6} \mathrm{H}_{8} \mathrm{O}_{6}, \mathrm{MM}\right.$ $176,13 \mathrm{~g} \mathrm{~mol}^{-1}$, Merck) $0,177 \mathrm{mg} \mathrm{mL}^{-1}$ foi preparada diariamente por dissolução de $0,04443 \mathrm{~g}$ em água em balão volumétrico de $250 \mathrm{~mL}$.

Reagente CUPRAC foi preparado pela mistura de $0,75 \mathrm{~mL}$ de solução de $\mathrm{Cu}\left(\mathrm{ClO}_{4}\right)$, $9,31 \times 10^{-2} \mathrm{~mol} \mathrm{~L}^{-1}, 3,0 \mathrm{~mL}$ de solução de acetato de amônio $3,0 \mathrm{~mol} \mathrm{~L}^{-1}$ e $15,0 \mathrm{~mL}$ de solução de $\mathrm{NC} 1,22 \times 10^{-2} \mathrm{~mol} \mathrm{~L}^{-1}$, completando o volume com álcool etilico (99,5\%, Synth) em um balão volumétrico de $50 \mathrm{~mL}$.

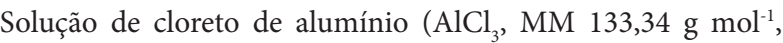
Fluka) $1,0 \%$ foi preparada dissolvendo $0,10 \mathrm{~g}$ em álcool etílico (99,5\%, Synth) em balão volumétrico de $10,0 \mathrm{~mL}$.

Solução de ácida de vanilina $\left(\mathrm{C}_{8} \mathrm{H}_{8} \mathrm{O}_{3}, 152,13 \mathrm{~g} \mathrm{~mol}^{-1}\right.$, J. T. Baker) $1,0 \%$ foi preparada dissolvendo $0,10 \mathrm{~g}$ em 10,00 $\mathrm{mL}$ de ácido clorídrico concentrado (36,5\%, 1,18 $\mathrm{g} \mathrm{cm}^{-3}$, Synth).

Reagente de Carr-Price foi preparado dissolvendo 2,5 g de cloreto de antimônio ( $\mathrm{SbCl}_{3}, \mathrm{MM} 228,11 \mathrm{~g} \mathrm{~mol}^{-1}$, Riedel-de-Haeën)

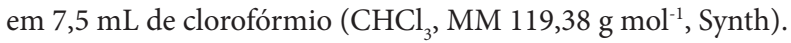

Solução de água oxigenada $10 \mathrm{~V}$ (solução de $\mathrm{H}_{2} \mathrm{O}_{2} \quad 3 \%$, Rioquímica Ind. Farm.).

Solução tampão fosfato (PBS) $\mathrm{pH}$ 7,6 foi preparada pela mistura de $39,5 \mathrm{~mL}$ de solução de hidróxido de sódio $(\mathrm{NaOH}, \mathrm{MM}$ 40,00 $\mathrm{g} \mathrm{mol}^{-1}$, Merck) 0,050 mol L-1 com 50,0 mL de solução de dihidrogenofosfato de sódio $\left(\mathrm{NaH}_{2} \mathrm{PO}_{4} \cdot \mathrm{H}_{2} \mathrm{O}, \mathrm{MM} \mathrm{137,} 99 \mathrm{~g} \mathrm{~mol}^{-1}\right.$, Ecibra) 0,0500 $\mathrm{mol} \mathrm{L}^{-1}$ para um balão de volumétrico de 100,0 mL e o volume completado com água. 


\section{Procedimento experimental}

\section{Preparação das amostras de chás}

As amostras de ervas de chás de diferentes espécies vegetais e de várias marcas comerciais (Dr. Oetker, Lin Tea, Coop, Leão, Dia, Hikari, Apichá, Ekonomico, Carrefour, Yamamotoyama, Nutrichá e Real) foram adquiridas em supermercados da Grande São Paulo. Todo o material estava seco, acondicionado em sachets e dentro do prazo de validade estabelecido pelo fabricante.

A extração dos compostos hidrossolúveis do material seco originando o chá foi efetuada por infusão. Água foi aquecida até a fervura e transferiram-se $250 \mathrm{~mL}$ para uma caneca na qual o sachet foi imerso repetidas vezes durante três minutos. A massa do material seco utilizada para o cálculo da CAT foi obtida pela média das pesagens do conteúdo de três sachets da mesma embalagem.

\section{Determinação do teor total de polifenol}

Este ensaio é baseado na redução do reagente de FC pelos compostos fenólicos em meio alcalino ( $\mathrm{pH} \cong 10)$ ajustado com solução de $\mathrm{Na}_{2} \mathrm{CO}_{3}$ a $10 \%$ com a formação de solução de cor azul, cujas medições de absorbância em 715 nm são relacionadas ao conteúdo total de polifenol ${ }^{27}$, expresso em ácido gálico ${ }^{15}$.

\section{Curvas de calibração}

Alíquotas de 50 a $350 \mu \mathrm{L}$ da solução de ácido gálico, AG, 0,0188 $\mathrm{mg} \mathrm{mL}^{-1}$ foram transferidas separadamente para uma série de sete balões volumétrico de 5,0 $\mathrm{mL}$ contendo $200 \mathrm{~mL}$ do reagente de FC, os quais foram completados com solução de $\mathrm{Na}_{2} \mathrm{CO}_{3}$ a $10 \%$. A concentração final da solução de $\mathrm{AG}$ variou de $1,88 \times 10^{-4}$ a $1,32 \times 10^{-3} \mathrm{mg} \mathrm{mL}^{-1}$. Após 30 minutos, as leituras de absorbância (A) foram realizadas em $715 \mathrm{~nm}$ utilizando água como solução de referência (branco). Com o gráfico de calibração $\left(\mathrm{A}_{715 \mathrm{~nm}}\right.$, $\mathrm{ab}-$ sorbância em $715 \mathrm{~nm}$ vs $\mathrm{C}_{\mathrm{AG}}$, concentração de $\mathrm{AG}$ em mg mL $\mathrm{mL}^{-1}$ ) obteve-se a reta $\mathrm{A}_{715 \mathrm{~mm}}=\mathrm{a}+\mathrm{b} \times \mathrm{C}_{\mathrm{AG}}$, em que $a$ e $b$ são, respectivamente, os valores dos coeficientes linear e angular.

\section{Cálculo do TTP}

Amostras de chá recém preparadas foram diluídas 25 vezes. Alíquotas variando de 250 a $1.000 \mu \mathrm{L}$ (dependendo do tipo de chá) foram transferidas para balões volumétricos de 5,0 mL contendo $200 \mathrm{~mL}$ do reagente de $\mathrm{FC}$, os quais foram completados com solução de $\mathrm{Na}_{2} \mathrm{CO}_{3}$ a 10\%. Após 30 minutos, as leituras de absorbância foram realizadas em $715 \mathrm{~nm}$ utilizando água como branco. O TTP foi deduzido a partir da reta da curva de calibração $A_{715 n m}=a+b \times C_{A G}$ e o valor, expresso em $C_{A G}$. Todas as medições foram feitas em triplicata e, depois de corrigidas as diluições efetuadas, expressou-se o TTP em mg AG/g material seco.

\section{Determinação da atividade antioxidante com o método CUPRAC}

$\mathrm{O}$ reagente cromogênico utilizado nesse método é formado pelos complexos de $\mathrm{Cu}(\mathrm{II})$ com NC em solução hidroetanólica em
pH 7,0 mantido com solução de $\mathrm{CH}_{3} \mathrm{COONH}_{4}$. Quando certos agentes redutores são adicionados a essa solução, $\mathrm{Cu}^{2+}$ é reduzido a $\mathrm{Cu}^{+}$, formando complexos de $\mathrm{Cu}(\mathrm{I}) / \mathrm{NC}$ cor laranja intensa com máximo valor de absorbância em $454 \mathrm{~nm}$.

\section{Curvas de calibração com ácido ascórbico}

Alíquotas de 50 a $350 \mu \mathrm{L}$ da solução de ácido ascórbico, AA, $0,177 \mathrm{mg} \mathrm{mL}^{-1}$ foram transferidas separadamente para uma série de sete frascos de 5,0 $\mathrm{mL}$ contendo 2,5 $\mathrm{mL}$ do reagente CUPRAC, os quais foram completados com água. A concentração final de AA variou de $1,76 \times 10^{-3}$ a $1,23 \times 10^{-2} \mathrm{mg} \mathrm{mL}^{-1}$. Após 30 minutos, as leituras de absorbância (A) foram realizadas em $454 \mathrm{~nm}$. Uma mistura 1:1 (v/v) recém-preparada do reagente CUPRAC em água foi usada como solução de referência. Com o gráfico de calibração ( $\mathrm{A}_{454 \mathrm{~nm}}$, absorbância em $454 \mathrm{~nm} v s \mathrm{C}_{\mathrm{AA}}$, concentração de ácido ascórbico, em mg mL${ }^{-1}$ ) obteve-se a reta $\mathrm{A}_{454 \mathrm{~nm}}=\mathrm{a}+\mathrm{b} \times \mathrm{C}_{\mathrm{AA}}$, onde $a$ e $b$ são, respectivamente, os valores dos coeficientes linear e angular.

\section{Determinação da atividade antioxidante das amostras de chá}

Todas as soluções de chá recém preparadas foram diluídas 25 vezes. Transferiram-se cinco alíquotas entre 100 e $1750 \mu \mathrm{L}$ (dependendo do tipo de chá) para balões volumétricos de 5,0 mL, os quais continham 2,5 mL do reagente CUPRAC, completando-se em seguida com água.

A concentração do material seco em cada balão foi expressa em $\mathrm{mg} \mathrm{mL} \mathrm{m}^{-1}$. Após 30 minutos, as leituras em $\mathrm{A}_{454 \mathrm{~nm}}$ foram realizadas usando mistura recém-preparada do reagente CUPRAC em água 1:1 (v/v) como solução de referência.

Construiu-se uma curva de calibração $\left(\mathrm{A}_{454 \mathrm{~nm}}\right.$ vs $\mathrm{C}_{\mathrm{MS}}$, concentração do material seco, em $\mathrm{mg} \mathrm{mL}^{-1}$ ) obtendo-se a reta $\mathrm{A}_{454 \mathrm{~nm}}=\mathrm{a}+\mathrm{b} \times \mathrm{C}_{\mathrm{MS}}$, onde $a$ e $b$ são, respectivamente, os valores dos coeficientes linear e angular.

\section{Metodologia de cálculo}

Para a obtenção dos valores da CAT das amostras de chá, os resultados foram expressos em $\mathrm{g}$ de AA e calculados da forma como segue. Supondo concentração teórica de $1,0 \mathrm{mg} \mathrm{mL}^{-1}$ de AA, calculou-se, utilizando a equação $\mathrm{A}_{454 \mathrm{~nm}}=\mathrm{a}+\mathrm{b} \times \mathrm{C}_{\mathrm{AA}}$, o valor teórico de $\mathrm{A}_{454 \mathrm{~nm}}$ correspondente a essa concentração. Substituiu-se o valor teórico na equação $A_{454 \mathrm{~nm}}=\mathrm{a}+\mathrm{b} \times \mathrm{C}_{\mathrm{MS}}$, obtendo-se a concentração de material seco, $\mathrm{C}_{\mathrm{MS}}$, também em $\mathrm{mg} \mathrm{mL}^{-1}$. Esse valor correspo de matematicamente à concentração do chá (em $\mathrm{mg} \mathrm{mL}^{-1}$ ), o que equivale à CAT de uma solução de AA $1,0 \mathrm{mg} \mathrm{mL}^{-1}$.

Depois de corrigida a diluição efetuada (25 vezes), encontrou-se a massa de chá (em g) responsável por essa atividade antioxidante, a qual foi comparada com a massa total de amostra de chá (material seco) presente no balão volumétrico de $250 \mathrm{~mL}$. O valor da CAT de cada amostra de chá foi expresso em g material seco/g AA (Tabela 1).

\section{Scavenging com peróxido de hidrogênio $\left(\mathrm{H}_{2} \mathrm{O}_{2}\right)$}

$\mathrm{O}$ princípio deste método reside na medida da diminuição do valor de absorvância de uma solução diluída de $\mathrm{H}_{2} \mathrm{O}_{2}$ após a 
Tabela 1: Valores de teor total de polifenol, capacidade antioxidante total, scavenging de $\mathrm{H}_{2} \mathrm{O}_{2}$ e a presença de flavonóides, catequinas e carotenos das 43 amostras de chá analisadas

\begin{tabular}{|c|c|c|c|c|c|c|c|c|}
\hline Chá & Nome científico & Parte usada & TTP & $\mathrm{CAT}_{\text {EAA }}$ & Scavenging $\%$ & Flavonóides & Catequinas & Carotenos \\
\hline Hortelã 1 & Mentha piperita L. & Folhas e ramos & 61,4 & 44,4 & 17,4 & +++ & ++ & ++ \\
\hline Hortelã 2 & $\begin{array}{c}\text { Mentha piperita L. e/ou } \\
\text { Mentha arvensis L. }\end{array}$ & $\begin{array}{l}\text { Folhas e parte } \\
\text { do ramo }\end{array}$ & 83,1 & 29,4 & 13,6 & + & +++ & +++ \\
\hline Hortelã 3 & Mentha arvensis L. & Folhas e caule & 47,8 & 200 & 7,96 & NO & NO & NO \\
\hline Hortelã 4 & Mentha piperita L. & $\begin{array}{l}\text { Folhas e parte } \\
\text { do ramo }\end{array}$ & 109 & 78,3 & 8,20 & ++ & +++ & +++ \\
\hline Hortelã 5 & Mentha piperita L & Folhas & 82,6 & 40,2 & 6,24 & + & ++ & ++ \\
\hline Hortelã 6 & Mentha arvensis L. & Folhas e ramos & 47,0 & 201 & 22,9 & NO & ++ & ++ \\
\hline Erva cidreira 1 & Cymbopogon citratus S. & Folhas & 7,90 & 43,8 & 13,6 & + & ++ & ++ \\
\hline Erva cidreira 2 & Cymbopogon citratus S. & Folhas & 10,2 & 21,8 & 23,2 & NO & ++ & ++ \\
\hline Erva cidreira 3 & Melissa officinalis L. & Folhas & 1,56 & 200 & 36,9 & NO & ++ & ++ \\
\hline Erva cidreira 4 & Cymbopogon citratus S. & $\begin{array}{l}\text { Folhas e } \\
\text { capítulos }\end{array}$ & 8,22 & 122 & 10,0 & + & ++ & ++ \\
\hline Erva doce 1 & Pimpinella anisum L. & Frutos & 8,18 & 13,9 & 7,63 & + & ++ & ++ \\
\hline Erva doce 2 & Pimpinella anisum L. & Sementes & 6,70 & 12,0 & 9,64 & NO & ++ & ++ \\
\hline Erva doce 3 & Foeniculum vulgare Mill. & Frutos & 64,7 & 8,50 & 24,1 & NO & ++ & NO \\
\hline Erva doce 4 & Pimpinella anisum L. & Frutos & 6,19 & 8,90 & 24,1 & + & ++ & ++ \\
\hline Camomila 1 & Matricaria recutita L. & Capítulos florais & 12,0 & 307 & 16,3 & ++ & +++ & +++ \\
\hline Camomila 2 & Matricaria recutita L. & Capítulos florais & 16,6 & 193 & 2,19 & +++ & +++ & ++ \\
\hline Camomila 3 & Matricaria recutita L. & Capítulos florais & 9,60 & 218 & 8,21 & +++ & +++ & ++ \\
\hline Camomila 4 & Matricaria chamomilla L. & $\begin{array}{l}\text { Flores e } \\
\text { pedúnculos }\end{array}$ & 14,9 & 182 & 4,12 & +++ & +++ & ++ \\
\hline Camomila 5 & Matricaria recutita L. & Flores & 12,8 & 176 & 10,7 & +++ & +++ & ++ \\
\hline Camomila 6 & $\begin{array}{c}\text { Matricaria recutita e/ou } \\
\text { Chamomilla recutita (L.) } \\
\text { Rauscher }\end{array}$ & $\begin{array}{l}\text { Florais e } \\
\text { capítulos }\end{array}$ & 8,70 & 274 & 12,4 & +++ & +++ & +++ \\
\hline Camomila 7 & Matricaria recutita L. & Florais & 13,8 & 218 & 6,51 & + & ++ & ++ \\
\hline Mate 1 & Ilex paraguariensis St.Hill & Folhas e talos & 60,9 & 18,1 & 20,0 & +++ & +++ & ++ \\
\hline Mate 2 & Ilex paraguariensis St.Hill & Folhas e talos & 69,5 & 19,7 & 9,00 & +++ & +++ & +++ \\
\hline Mate 3 & Ilex paraguariensis St.Hill & Folhas e talos & 51,9 & 39,8 & 9,91 & ++ & ++ & ++ \\
\hline Boldo 1 & Peumus boldus, Molina & Folhas & 29,6 & 47,0 & 16,1 & NO & +++ & NO \\
\hline Boldo 2 & Peumus boldus, Molina & Folhas & 56,7 & 37,8 & 44,5 & ++ & +++ & +++ \\
\hline Boldo 3 & Peumus boldus, Molina & Folhas & 64,7 & 28,5 & 26,7 & + & +++ & ++ \\
\hline Boldo 4 & Peumus boldus, Molina & Folhas & 55,7 & 39,2 & 2,57 & + & +++ & + \\
\hline Boldo 5 & Peumus boldus, Molina & Folhas & 57,8 & 39,0 & 7,14 & + & ++ & + \\
\hline Carqueja 1 & $\begin{array}{l}\text { Baccharis genisteiloides } \\
\text { (Lamarck) Person }\end{array}$ & Folhas & 15,2 & 62,4 & 6,28 & NO & +++ & NO \\
\hline Carqueja 2 & Baccharis genisteiloides & Folhas & 9,17 & 126 & 19,4 & NO & +++ & NO \\
\hline Carqueja 3 & $\begin{array}{l}\text { Baccharis genisteiloides } \\
\text { (Lamarck) Person }\end{array}$ & Folhas & 12,0 & 106 & 16,1 & ++ & ++ & + \\
\hline Chá verde 1 & $\begin{array}{l}\text { Camellia sinensis (L.) } \\
\text { Kuntze }\end{array}$ & Folhas e talos & 55,5 & 16,6 & 26,6 & + & +++ & NO \\
\hline Chá verde 2 & Camellia sinensis L. & Folhas & 16,7 & 59,1 & 28,4 & ++ & +++ & NO \\
\hline Chá verde 3 & Camellia sinensis L. & Folhas e brotos & 71,8 & 19,5 & 27,3 & ++ & +++ & + \\
\hline Chá preto 1 & $\begin{array}{l}\text { Camellia sinensis (L.) } \\
\text { Kuntze }\end{array}$ & Folhas e talos & 57,4 & 22,0 & 16,5 & NO & +++ & NO \\
\hline Chá preto 2 & $\begin{array}{l}\text { Camellia sinensis (L.) } \\
\text { Kuntze }\end{array}$ & Folhas e talos & 83,2 & 18,2 & 23,4 & + & +++ & + \\
\hline Chá preto 3 & Camellia sinensis $\mathrm{L}$. & Folhas & 59,8 & 16,7 & 14,4 & NO & +++ & + \\
\hline Chá preto 4 & Camellia sinensis L. & Folhas & 52,3 & 10,4 & 21,5 & NO & +++ & + \\
\hline Chá branco 1 & $\begin{array}{l}\text { Camellia sinensis (L.) } \\
\text { Kuntze }\end{array}$ & $\begin{array}{c}\text { Folhas jovens e } \\
\text { brotos }\end{array}$ & 77,5 & 14,1 & 28,5 & NO & +++ & NO \\
\hline Chá branco 2 & $\begin{array}{c}\text { Camellia sinensis (L.) } \\
\text { Kuntze }\end{array}$ & Brotos de folhas & 121 & 14,8 & 14,0 & NO & +++ & NO \\
\hline Chá branco 3 & $\begin{array}{l}\text { Camellia sinensis (L.) } \\
\text { Kuntze }\end{array}$ & Folhas & 93,5 & 14,5 & 22,7 & NO & +++ & + \\
\hline Chá branco 4 & Camellia sinensis L. & $\begin{array}{c}\text { Folhas jovens } \\
\text { e brotos }\end{array}$ & 74,5 & 21,0 & 5,84 & + & +++ & ++ \\
\hline
\end{tabular}

Os nomes científicos e as partes usadas das plantas são informações disponíveis nas embalagens dos produtos; TTP: teor total de polifenol (expresso em mg ácido

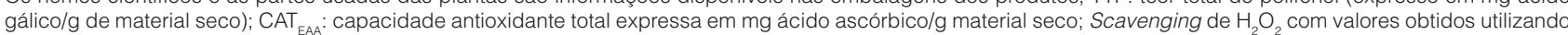
alíquota de $200 \mathrm{~mL}$ de chá; (+): Presença; NO: não observado 
oxidação da mesma com agentes redutores, nesse caso as substâncias presentes nas amostras de chás. $\mathrm{O}$ ensaio foi adaptado do procedimento recomendado por Ruch, Cheng e Klainig ${ }^{28}$ com medições dos valores de absorbância em $230 \mathrm{~nm}, \mathrm{~A}_{230 \mathrm{~nm}}$, antes e após a adição da amostra de chá, depois de dez minutos.

\section{Metodologia de cálculo do scavenging de $\mathrm{H}_{2} \mathrm{O}_{2}$ nas amostras}

Soluções diluídas de $\mathrm{H}_{2} \mathrm{O}_{2} 4,4 \mathrm{mmol} \mathrm{L}^{-1}$ foram preparadas em quatro balões volumétricos de $5,0 \mathrm{~mL}$ contendo solução tampão PBS $0,02 \mathrm{~mol} \mathrm{~L}^{-1}$.

No primeiro, obteve-se o valor de absorbância da solução controle $\left(\mathrm{Ac}_{\mathrm{H} 2 \mathrm{O} 2}\right)$ descontando o valor de $\mathrm{A}_{230 \mathrm{~nm}}$ de uma solução contendo somente PBS 0,02 $\mathrm{mol} \mathrm{L}^{-1}$.

Nos outros três balões, adicionaram-se alíquotas de 100, 200 e $300 \mu \mathrm{L}$ do chá recém-preparado, completando o volume com água. Nesses balóes os valores de absorbância na presença de chá $\left(\mathrm{As}_{\mathrm{H} 2 \mathrm{O} 2}\right)$ foram obtidos descontando-se o valor de $\mathrm{A}_{230 \mathrm{~nm}}$ de uma solução contendo a mesma alíquota de chá e PBS 0,02 mol L-1.

A porcentagem de scavenging de $\mathrm{H}_{2} \mathrm{O}_{2}$ atribuída aos compostos presentes nas amostras de chá foi calculada pela equação:

$\%=\left[\left(\mathrm{Ac}_{\mathrm{H} 2 \mathrm{O} 2}-\mathrm{As}_{\mathrm{H} 2 \mathrm{O} 2}\right) / \mathrm{Ac}_{\mathrm{H} 2 \mathrm{O} 2}\right] \times 100$

\section{Detecção de outros de compostos AO's por cromatografia em papel}

Nestes ensaios, o papel cromatográfico contendo a amostra foi pulverizado com a solução do reagente específico, seguido de um tratamento recomendado. Em seguida, o papel cromatográfico foi transferido para o transiluminador e verificou-se a presença de compostos investigados diretamente sobre a luz UV.

Como esse tipo de ensaio é semiquantitativo, os resultados obtidos não foram expressos numericamente (Tabela 1). A amostra que apresentou maior intensidade de cor foi assinalada como $(+++)$ e a de menor coloração $(+)$.

\section{Flavonóides}

Gotas de chá recém-preparado foram transferidas para o papel cromatográfico e, em seguida, pulverizou-se com solução de cloreto de alumínio a 1,0\%. O aparecimento de mancha amarela fluorescente sob luz UV indica a presença de flavonóides ${ }^{29}$.

\section{Catequinas}

Gotas de chá recém preparado foram transferidas para o papel de cromatografia e em seguida pulverizou-se com solução ácida de vanilina a 1,0\%. Após secagem do papel à temperatura ambiente, a presença de catequinas é indicada pela formação de manchas vermelhas sob luz $\mathrm{UV}^{29}$.

\section{Carotenos}

Gotas de chá recém preparado foram transferidas para o papel de cromatografia e em seguida pulverizou-se com reagente de
Carr-Price. O papel foi colocado em estufa a $100^{\circ} \mathrm{C}$ por $10 \mathrm{minu}-$ tos. O aparecimento de manchas vermelhas fluorescentes sob luz UV indica a presença de carotenos ${ }^{29}$.

\section{RESULTADOS E DISCUSSÃO}

Várias pesquisas são encontradas na literatura sobre a quantificação da CAT e do TTP de espécies vegetais brasileiras, mas a maioria dos trabalhos está direcionada para estudos utilizando partes dessas ervas (folhas, caule, sementes, etc.) logo após a colheita. São relativamente poucos os estudos que utilizam essas espécies vegetais na forma como são encontradas pelos consumidores para elaboração da infusão (comumente denominado chá). Um estudo dessa natureza é digno de investigação e, por isso, no presente trabalho, utilizaram-se como amostras somente ervas para chás comercializados em sachets e disponíveis em mercados da Grande São Paulo.

Embora os procedimentos encontrados na literatura sejam semelhantes (variando a massa de material seco de 1,0 a 1,5 g em um volume final de água de $100-250 \mathrm{~mL}$ ), parece não haver uma forma padronizada para a preparação de amostra de chás para a análise $e^{5,11,30,31}$. Em todas as análises do presente trabalho as amostras de chá foram preparadas com o sachet fechado da mesma forma como aquela ingerida pelo consumidor e de maneira semelhante à efetuada em outro trabalho ${ }^{30}$.

Em relação ao solvente, sabe-se que o uso do etanol aumenta a extração dos compostos fenólicos dos chás, bem como sua atividade antibacteriana ${ }^{3}$, mas, no presente estudo, a água foi usada como solvente extrator novamente para simular o uso cotidiano desse produto.

O tempo de infusão e a temperatura também alteram a extração de compostos polifenólicos. Campanella, Bonanni e Tomassetti afirmam que cinco minutos (utilizando água quente) é o tempo ótimo para a extração dos compostos antioxidantes do chá. Após isso, esses compostos precipitam ou formam micelas, diminuindo o TTP e a CAT do extrato vegetal ${ }^{32}$. Por isso, neste trabalho se estabeleceu o tempo fixo de três minutos após a adição de água quente.

A Tabela 1 apresenta os resultados obtidos com as 43 amostras de 10 diferentes tipos de ervas de chás analisadas, com os valores do TTP, da atividade antioxidante, da porcentagem de scavenging com $\mathrm{H}_{2} \mathrm{O}_{2}$ e também da presença de flavonóides, catequinas e carotenos.

\section{Teor total de polifenol}

Os resultados do TTP das amostras analisadas, obtidos com o reagente de FC, foram expressos em mg ácido gálico/g de material seco. Com esses valores foram obtidas as médias do TTP para os 10 tipos de chás analisados: hortelã $(64,4 \pm 17,8)$; erva cidreira $(8,8 \pm 1,2)$ erva doce $(7,0 \pm 1,0)$; camomila $(12,6 \pm 1,8)$; mate $(60,8 \pm 8,8)$; boldo $(52,9 \pm 13,5)$; carqueja $(12,1 \pm 3,0)$; verde $(48,0 \pm 28,3)$; preto $(63,2 \pm 13,7)$ e branco $(91,7 \pm 21,4)$, conforme pode ser visto na Figura 1. Nesse cálculo, os valores das amostras 


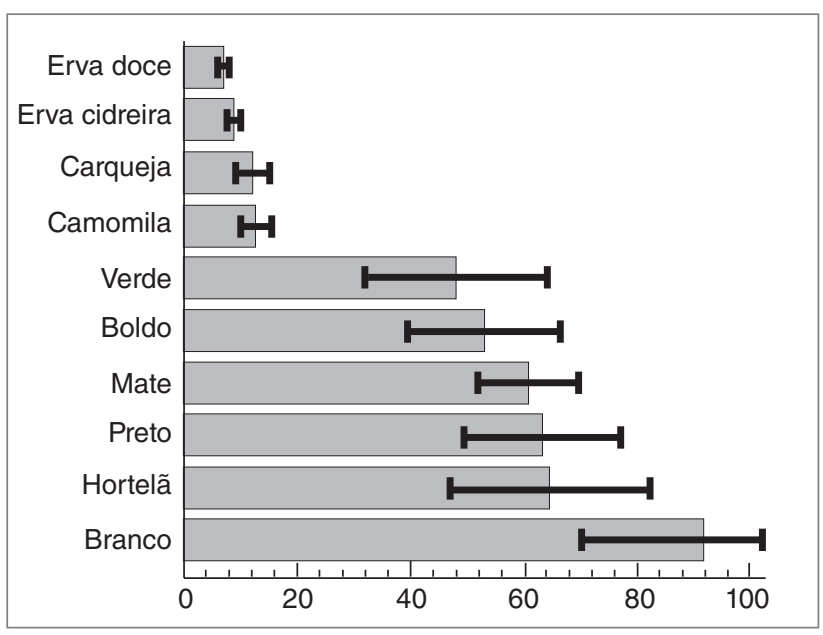

Figura 1: Teor total de polifenol (TTP) para diversos tipos de chás

hortelã $n^{\circ} 4$ (110), erva cidreira $n^{\circ} 3(64,7)$ e erva doce $n^{\circ} 3(1,56)$ tiveram de ser retirados do cálculo da média por apresentarem valores muito discordantes do grupo.

As divergências encontradas no TTP para a mesma espécie podem ser atribuídas ao fato das plantas terem sido coletadas de fontes com características geográficas (local de plantio) distintas e condições do cultivo (tipo de solo e variações climáticas) diferentes. Além disso, a parte da planta utilizada (assim como o seu grau de desenvolvimento) para a preparação do material seco pode influenciar no TTP e, segundo informações presente nas embalagens, somente os chás de boldo, mate e carqueja foram preparados com a mesma parte da planta.

Embora o estabelecimento de uma classificação com base no TTP de cada variedade dos chás necessite de uma amostragem maior (para evitar conclusões enganosas), nota-se que os chás de erva doce e cidreira apresentam o menor valor de TTP (7 a 9 mg AG/g material seco, respectivamente) enquanto o chá branco apresenta o maior TTP (92 mg AG/g material seco).

Apesar dos chás branco, verde e preto serem elaborados com as folhas da mesma espécie vegetal (Camelia sinensis L.), o TTP não é o mesmo para os três chás (chás verde $=48,0 \mathrm{mg} \mathrm{AG} / \mathrm{g}$ material seco e chá preto $=63,2 \mathrm{mg} \mathrm{AG} / \mathrm{g}$ material seco). Isso pode ser atribuído ao grau de fermentação ao qual as folhas são submetidas, o que afeta o perfil dos componentes polifenólicos do chá3 ${ }^{33}$. No chá branco, usam-se folhas jovens e que ainda não sofreram processo de fermentação; no chá verde as folhas secas sofrem leve fermentação com pouca oxidação durante o processamento; e no chá preto o processo de fermentação é o mais intenso.

\section{Capacidade antioxidante total}

Estudos demonstram que os valores obtidos para a CAT de extratos vegetais variam em função do tipo de solvente usado no processo de extração, como n-hexano e acetona ${ }^{34}$, ligroína (éter de petróleo), acetato de etila, etanol e éter dietílico ${ }^{35}$, ou n-hexano e metanol. Como não há muita informação sobre os valores da
CAT em infusões aquosas, optou-se, neste trabalho, pelo uso da água como solvente.

A Tabela 1 mostra variação no valor da CAT entre os grupos de chá avaliados, a qual pode ser explicada pelas mesmas razões atribuídas às diferenças encontradas na quantificação do TTP. Além disso, o processo para embalagem da ervas nos envelopes, incluindo a possível inclusão de excipientes nas formulações dos sachets, pode levar a uma alteração significativa da atividade antioxidante ${ }^{31,36,37}$.

Valores médios de CAT (expressos em mg AA/g material seco) obtidos com o método CUPRAC para as amostras de chás avaliadas foram calculados retirando as amostras hortelã $\mathrm{n}^{\circ} 4(110)$, erva cidreira $n^{\circ} 3(64,7)$ e erva doce $n^{\circ} 3(1,56)$ as quais apresentaram valores muito divergentes do grupo. Com os valores da Tabela 1 é possível elaborar uma ordem de atividade antioxidante, sendo: camomila $(22,4)>$ hortelã $(10,3)>$ carqueja $(9,81)>$ cidreira $(6,25)>$ boldo $(3,83)>$ verde $(3,17) \approx$ mate $(2,59)$; preto $(1,68)$ $\approx$ branco $(1,62)>$ erva doce $(1,16)$.

Considerando, porém, os três chás da mesma espécie vegetal (Camelia sinensis), o valor médio da CAT das amostras de chá preto analisadas é $\approx 50 \%$ menor que o valor médio da CAT de chá verde. Benzie e Szeto ${ }^{38}$ atribuíram essa diferença à interação de alguns antioxidantes presentes no chá verde (principalmente catequinas).

Devido à dificuldade de adotar um único procedimento para a determinação da atividade antioxidante, e considerando que os polifenóis devem ser os compostos que mais favorecem a CAT, outros procedimentos específicos, além da quantificação do TTP, devem ser realizados. Isso porque os polifenois têm atividades múltiplas e a atividade dominante depende do meio e do substrato de teste ${ }^{7}$.

\section{Scavenging com peróxido de hidrogênio $\left(\mathrm{H}_{2} \mathrm{O}_{2}\right)$}

Para todas as amostras de chá analisadas, a porcentagem de $s c a-$ venging com $\mathrm{H}_{2} \mathrm{O}_{2}$ aumentou de acordo com alíquota de chá adicionada $(100,200$ ou $300 \mu \mathrm{L})$. A Tabela 1 apresenta os resultados obtidos somente com o ensaio de scavenging utilizando $200 \mathrm{~mL}$ de chá.

Considerando todas as amostras analisadas para o mesmo volume de $200 \mathrm{~mL}$, observa-se grande variação da porcentagem de scavenging para um mesmo tipo de chá. Os valores do coeficiente de variação, a relação percentual entre o desvio-padrão e a média dos valores obtidos (CV) para a porcentagem de scavenging das amostras de chás de carqueja, branco, hortelã, cidreira, doce e camomila variaram de 50 a $55 \%$. Para as amostras de chá mate e boldo, os valores de CV foram $\approx 85$ a $90 \%$. Exceção foi verificada para as amostras de chá verde que apresentaram a menor difererença entre os tipos de chás analisados $(\mathrm{CV} \approx 4 \%)$, o que poderia indicar razoável homogeneidade na composição fitoquímica nas folhas e brotos da planta utilizados da espécie Camelia sinensis.

Apesar disso, pode-se propor uma ordem de porcentagem de scavenging com $\mathrm{H}_{2} \mathrm{O}_{2}$ nos chás avaliados, sendo: verde $>$ cidreira $\approx$ boldo $\approx$ preto $\approx$ branco $>$ erva doce $\approx$ carqueja $\approx$ hortelã $>$ mate $\approx$ 
camomila. Embora os valores apresentados na Tabela 1 sejam resultado de experimentos in vitro, é possível verificar que as amostra de chá verde são mais eficientes na remoção de $\mathrm{H}_{2} \mathrm{O}_{2}$, que é uma das principais ROS intracelulares e que em modelo animal se mostrou potencialmente geradora de câncer ${ }^{16}$.

A relação existente entre a porcentagem de scavenging e o TTP nas várias amostras de chás investigadas não é tão facilmente estabelecida. Observa-se (Tabela 1) o aumento da porcentagem de scavenging com o TTP somente para as amostras de erva doce, boldo e preto. No ensaio para a porcentagem de scavenging, outros compostos não polifenólicos de caráter redutor podem aumentar o consumo de $\mathrm{H}_{2} \mathrm{O}_{2}$.

\section{Flavonóides}

Matsubara $^{39}$ constatou a presença dos flavonóides quercetina e campferol em amostras de chá de boldo, e quercetina em chá de camomila, mas não detectou flavonóides em amostras de chás de erva doce, erva cidreira, hortelã, maçã e mate ${ }^{40}$. Em outro estudo, miricetina e quercetina foram identificadas em amostras de chás de camomila, erva doce, mate e hortelã e chás preto e verde ${ }^{5}$.

Na presente pesquisa, camomila e mate foram os grupos de chás que apresentaram flavonóides em todas as amostras analisadas, enquanto nas amostras de chá preto não se observou presença.

Nos outros tipos de chás analisados, a quantidade de flavonóides variou conforme a ordem: hortelã $\approx$ boldo $\approx$ verde $>$ cidreira $\approx$ doce $>$ carqueja $\approx$ branco. Neste último tipo, outros compostos AO's devem ser os responsáveis pelo alto TTP encontrado.

\section{Catequinas}

Os ensaios cromatográficos realizados mostraram que todas as amostras de chás contém catequinas (Tabela 1), mas os chás preto, verde e branco revelaram presença máxima $(+++)$ em todas elas.

Os três chás derivados da erva Camelia sinensis (preto, verde e branco) são uma fonte rica de catequinas, apesar de apresentarem diferentes tempos de fermentação. Outro estudo da literatura ${ }^{40}$ estabelece que o teor de catequinas nestes chás segue a ordem: branco (folhas jovens) > verde (folhas secas) > preto (folhas secas fermentadas). O chá verde tem mais catequinas que o preto pois, após a colheita, suas folhas passam pelo vapor, inibindo a oxidação destes compostos. Em seguida, as folhas secam naturalmente, o que permite preservar as catequinas que são convertidas a teaflavinas e tearubigenas durante o processo de oxidação para a obtenção do chá preto.

\section{Carotenos}

Neste trabalho foi observada a presença de carotenos em todas as amostras analisadas de chás de camomila, mate e cidreira. Nos grupos restantes, a quantidade de carotenos diminui de acordo com a ordem: hortelã $\approx$ doce $\approx$ boldo $>$ carqueja.

Todas as amostras de chás preto, verde e branco analisadas mostraram pouca presença de carotenos. Nessa espécie vegetal (Camelia sinensis L.), os carotenos não devem ser o grupo responsável pelo alto valor de TTP encontrado (Tabela 1).

\section{Conclusão}

No presente estudo, pela primeira vez, um grande número de ervas de chás comercialmente disponíveis em sachets na região da grande São Paulo foi avaliado com o objetivo de determinar a CAT com o método CUPRAC.

As ervas utilizadas na elaboração dos chás contêm compostos quimicamente muito diferentes, o que dificulta a adoção de um único método para avaliar a CAT. Todavia, o conjunto de ensaios aqui apresentado pode servir como um guia na escolha do chá a ser consumido ou mesmo como um modelo inicial de estudo para o controle de qualidade de produtos fitoterápicos.

Todos os chás aqui analisados apresentaram atividade antioxidante (em termos de redução do íon $\mathrm{Cu}(\mathrm{II})$ na presença do ligante $\mathrm{NC}$ ) e do scavenging de $\mathrm{H}_{2} \mathrm{O}_{2}$, indicando, assim, possíveis benefícios para a saúde quando consumido apropriadamente.

\section{AGRADECIMENTOS}

À FAPESP (Fundação de Amparo à Pesquisa do Estado de São Paulo) e ao PIBIC (Programa Institucional de Bolsas de Iniciação Científica)/CNPq (Conselho Nacional de Desenvolvimento Científico e Tecnológico).

\section{REFERÊNCIAS}

1. Willet WC, Skerrett PJ. Eat, drinki and be healthy. The Harvard Medical School Guide to Healthy Eating. New York: Harvard Medical School; 2001.

2. Kaur C, Kapoor HC. Antioxidants in fruits and vegetables - the millennium's health. Int J Food Sci Technol. 2001;36(7):703-25.

3. Asolini FC, Tedesco AM, Carpes ST, Ferraz C, Alencar SM. Atividade antioxidante e antibacteriana dos compostos fenólicos dos extratos de plantas usadas como chás. Braz J Food Technol. 2006;9(3):209-15
4. Elejalde Guerra Jl. Oxidative stress, diseases and antioxidant treatment. An Med Interna. 2001;18(6):326-35.

5. Moraes-de-Sousa RA, Oldoni TLC, Regitano-d'Arce MAB, Alencar SM. Antioxidant activity and phenolic composition of herbal infusions consumed in Brazil. Ciencia y Tecnologia Alimentaria. 2008;6(1):41-7

6. Ou B, Huang D, Hampsch-Woodill M, Flanagan JA, Deemer EK. Analysis of antioxidant activities of common vegetables employing oxygen radical absorbance capacity (ORAC) and ferric reducing 
antioxidant power (FRAP) assays: a comparative study. J Agric Food Chem. 2002;50(11):3122-8

7. Prior RL, Wu X, Schaich K. Standardized methods for the determination of antioxidant capacity and phenolics in foods and dietary supplements. J Agric Food Chem. 2005;53(10):4290-302

8. Nutraceuticals World [Internet]. Antioxidant testing: an ORAC update: Evaluating antioxidant capacity is challenging but ORAC and other associated methods may be the best solution amidst all of the confusion. Disponivel em: http://www. highbeam.com/doc/1G1-114704238.html. Acesso em: 17 jun. 2012

9. Yang CS, Wang H, Li GX, Yang Z, Guan F, Jin H. Cancer prevention by tea: evidence from laboratory studies. Pharmacol Res. 2011;64(2):113-22.

10. Fujiki H, Suganuma M. Green tea: an effective synergist with anticancer drugs for tertiary cancer prevention. Cancer Lett. 2012;324(2):119-25

11. Apak R, Güçlü K, Ozyürek M, Karademir SE, Erçag E. The cupric ion reducing antioxidant capacity and polyphenolic content of some herbal teas. Int J Food Sci Nutr. 2006;57(5-6):292-304.

12. Apak R, Güçlü K, Ozyürek M, Karademir SE. Novel total antioxidant capacity index for dietary polyphenols and vitamins $C$ and $E$, using their cupric ion reducing capability in the presence of neocuproine: CUPRAC method. J Agric Food Chem. 2004;52(26):7970-81

13. Rognisky V, Lissi EA. Review of methods to determine chain-breaking antioxidant activity in food. Food Chem. 2005;92(2):235-54.

14. Halliwell B. Antioxidants and human disease: a general introduction. Nutr Rev. 1997;55(1 pt 2):S44-9.

15. ANVISA. Farmacopéia Brasileira. $5^{a}$ ed. Brasília: Anvisa; 2010. p. 355-7.

16. Klein-Szanto AJ, Slaga TJ. Effects of peroxides on rodent skin: epidermal hyperplasia and tumor promotion. J Invest Dermatol. 1982;79(1):30-4.

17. Antunes F, Cadenas E. Cellular titration of apoptosis with steady state concentrations of $\mathrm{H}_{2} \mathrm{O}_{2}$ : submicromolar levels of $\mathrm{H}_{2} \mathrm{O}_{2}$ induce apoptosis through fenton chemistry independent of the cellular thiol state. Free Radic Biol Med. 2001;30(9):1008-18.

18. Ranganathan AC, Nelson KK, Rodriguez AM, Kim KH, Tower GB, Rutter JL, et al. Manganese superoxide dismutase signals matrix metalloproteinase expression via $\mathrm{H}_{2} \mathrm{O}_{2}$-dependent ERK1/2 activation. J Biol Chem. 2001;276(17):14264-70

19. Santanam N, Penumetcha M, Speisky H, Parthasarathy S. A novel alkaloid antioxidant, boldine and synthetic antioxidant, reduced form of RU486, inhibit the oxidation of LDL in-vitro and atherosclerosis in vivo in LDLR mice. Atherosclerosis. 2004;173(2):203-10

20. Wenzel U, Kuntz S, Brendel MD, Daniel $H$. Dietary flavone is a potent apoptosis inducer in human colon carcinoma cells. Cancer Res. 2000;60(14):3823-31.

21. Ahmed-Belkacem A, Pozza A, Muñoz-Martínez F, Bates SE, Castanys S, Gamarro F, et al. Flavonoid structure-activity studies identify 6-prenylchrysin and tectochrysin as potent and specific inhibitors of breast cancer resistance protein ABCG2. Cancer Res. 2005;65(11):4852-60.
22. Jung SK, Lee KW, Byun S, Kang NJ, Lim SH, Heo YS, et al Myricetin suppresses UVB-induced skin cancer by targeting fyn. Cancer Res. 2008;68(14):6021-9.

23. Kuzuhara T, Suganuma M, Fujiki H. Green tea catechin as a chemical chaperone in cancer prevention. Cancer Lett. 2008;261(1):12-20

24. Mossine VV, Chopra P, Mawhinney TP. Interaction of tomato lycopene and ketosamine against rat prostate tumorigenesis. Cancer Res. 2008;68(11):4384-91

25. Maccarrone M, Bari M, Gasperi V, Demming-Adams B. The photoreceptor protector zeaxanthin induces cell death in neuroblastoma cells. Anticancer Res. 2005;25(6B):3871-6.

26. Merck E. Métodos complexométricos de valoración con titriplex $3^{\mathrm{a}}$ ed. Darmstadt: Merck; 1972. p.33-4.

27. Folin $\mathrm{O}$, Ciocalteu V. On tyrosine and tryptophan determinations proteins. J Biol Chem. 1927;73(2):627-50

28. Ruch RJ, Cheng SJ, Klainig JE. Prevention of cytotoxicity and inhibition of intracellular communication by antioxidant catechins isolated from Chinese green tea. Carcinogen. 1989;10(6):1003-8.

29. Merck E. Reactivos de coloración para cromatografia em capa fina y em papel. Darmstadt: Merck; 1980. p. 29-107.

30. Lima VLAG, Melo EA, Lima DESL. Teor de compostos fenólicos totais em chás brasileiros. Braz J Food Technol. 2004;7(2):187-90.

31. Satoh E, Tohyama N, Nishimura M. Comparison of the antioxidant activity of roasted tea with green, oolong, and black teas. Int $J$ Food Sci Nutr. 2005;56(8):551-9

32. Campanella L, Bonanni A, Tomassetti M. Determination of the antioxidant capacity of samples of different types of tea, or of beverages based on tea or other herbal products, using a superoxide dismutase biosensor. J Pharm Biomed Anal 2003;32(4-5):725-36

33. Balentine DA, Wiseman SA, Bouwens LC. The chemistry of tea flavonoids. Crit Rev Food Sci Nutr. 1997;37(8):693-704

34. Chen Q, Shi H, Ho CT. Effects of rosemary extracts and major constituents on lipid oxidation and soybean lipoxygenase activity. J Am Oil Chem Soc. 1992;69(10):999-1002.

35. Kramer RE. Antioxidants in clove. J Am Oil Chem Soc 1985;62(1):111-3

36. Chevolleau S, Mallet JF, Ucciani E, Gamisans J, Gruber M Antioxidant activity in leaves of some Mediterranean plants. J Am Oil Chem Soc. 1992;69(12):1269-71.

37. Samuelsen AB. The traditional uses, chemical constituents and biological activities of Plantago major L. A review. J Ethnopharmacol. 2000;71(1-2):1-21

38. Benzie IF, Szeto YT. Total antioxidant capacity of teas by the ferric reducing/antioxidant power assay. J Agric Food Chem. 1999;47(2):633-6

39. Matsubara S. Polifenóis em chás comercializados no Brasil Tese (Mestrado) - Faculdade de Engenharia de Alimentos da Universidade Estadual de Campinas, Campinas, 2001. p. 90.

40. Dekker M, Verkerk R, van der Sluis AA, Khokhar S, Jongen WM. Analysing the antioxidant activity of food products: processing and matrix effects. Toxicol In Vitro. 1999;13(4-5):797-9. 